\title{
Microstructure Evolution in Fe and Fe-Cr Alloys with OKMC Methods
}

\author{
Maria J. CATURLA ${ }^{1}$, Maria J. ALIAGA ${ }^{1}$, Ignacio MARTIN-BRAGADO ${ }^{2}$, Ignacio DOPICO ${ }^{3}$, \\ Lorenzo MALERBA ${ }^{3}$, Mercedes HERNANDEZ-MAYORAL ${ }^{4}$ \\ ${ }^{1}$ Dept. Física Aplicada, Facultad de Ciencias, Fase II, University of Alicante (Alicante, Spain) \\ ${ }^{2}$ IMDEA Materials Institute, Getafe (Madrid, Spain) \\ ${ }^{3}$ SCK-CEN, Nuclear Materials Science Institute (Mol, Belgium) \\ ${ }^{4}$ CIEMAT, Division of Materials (Madrid, Spain)
}

The type of damage observed under transmission electron microscopy (TEM) in b.c.c. Fe and FeCr alloys under irradiation is very dependent on the irradiation conditions. At high doses the damage consists mostly of $1 / 2<111>$ and $<100>$ loops, which are considered to be of interstitial type [1, 2]. Depending on the type of irradiation and the irradiation conditions, the ratio of one type of loop with respect to the other changes, with situations in which only one of the two types of loops are observed. The formation of $\langle 100>$ loops is still a controversial issue, with different models arising in the last few years. Experimentally, even the nature of these loops (vacancy or interstitial type) is still under debate under certain situations. Moreover, the type of irradiation (ion implantation vs. neutron irradiation) also changes the type and distribution of these defects.

In an attempt to shed some light into this complex system, we have developed models to study the damage of $\mathrm{Fe}$ and $\mathrm{FeCr}$ under irradiation. We combine results from density function theory (DFT), molecular dynamics (MD) and object kinetic Monte Carlo (OKMC) to study the production and evolution of the damage to time scales that can be directly compared to experiments. In this work we will discuss one particular issue: the differences between ion implantation and neutron irradiation. Currently, ion implantation is commonly used to obtain information about defect production and defect evolution, in an attempt to build models for neutron damage. We will point out the differences and commonalities between the two types of irradiation in the particular case of $\mathrm{Fe}$, and those aspects that should be taken into consideration when building models for neutron irradiation from information obtained from ion implantation.

We will describe results of damage evolution in $\mathrm{Fe}$ using two different models for $<100>$ loop formation: one where $<100>$ loops are formed from the interaction between $1 / 2<111>$ loops (based on simulations by Marian [3] and Terentyev [4]) and a second one where two populations of loops are formed directly in the collision cascade and evolve independently. This last model is based on the observation of stable immobile clusters from DFT calculations [5]. The population of loops formed as a function of dose for different irradiation conditions is explored and results compared to experiments. The validity of the models and the influence of the different parameters are discussed. In particular, we will study how the mobility of $\langle 111\rangle$ interstitial loops changes both the total concentration of visible defects as well as the ratio of $<111>$ vs. $<100>$ loops and compare the results with experimental data available, as shown in the Fig. 1. In this case the experiments are from reference [1].

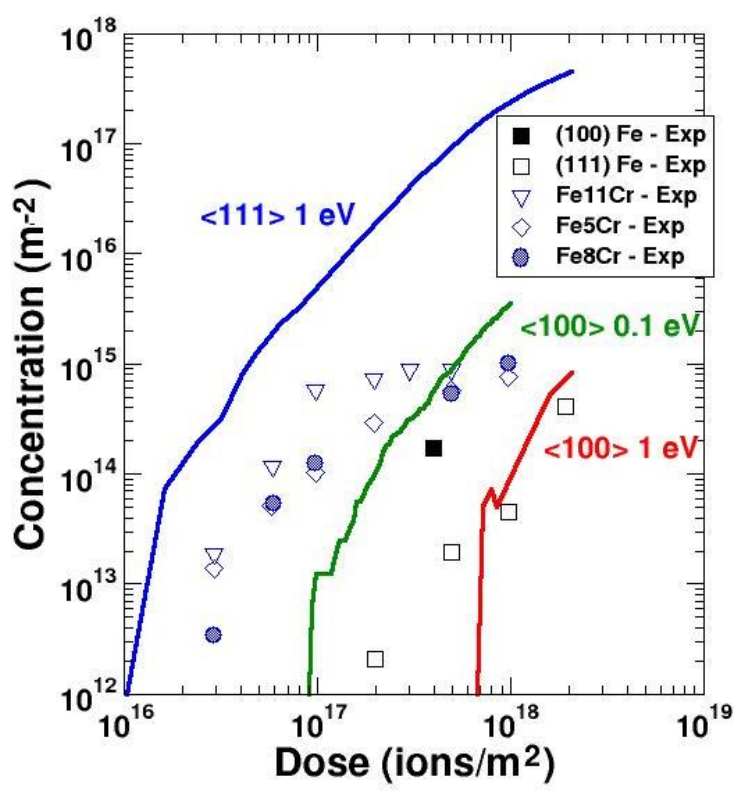

Figure 1: OKMC simulations (solid lines) compared to experiments from ref. [1] 
Finally we will discuss how object kinetic Monte Carlo can be modified to study high concentrated alloys for the particular case of FeCr.

\section{References}

[1] Z. Yao, M. Hernández Mayoral, M. L. Jenkins, M. A. Kirk, Heavy-ion irradiations of Fe and Fe-Cr model alloys Part 1: Damage evolution in thin-foils at lower doses, Phil. Mag. 88 (2008) 2851.

[2] M.L. Jenkins, Z. Yao, M. Hernández-Mayoral, M.A. Kirk, Dynamic observations of heavy-ion damage in Fe and Fe-Cr alloys, J. of Nucl. Mat. 389 (2009) 197-202.

[3] J. Marian, B. D. Wirth and J. Manuel Perlado, Mechanism of formation and growth of <100> interstitial loops in ferritic materials, Phys. Rev. Lett. 88, 25 (2002).

[4] Haixuan Xu, Roger E. Stoller, Yuri N. Osetsky and Dmitry Terentyev, Solving the puzzle of $<100>$ interstitial loop formation in bcc iron, Phys. Rev. Lett. 110, 265503 (2013).

[5] M.-C. Marinica, F. Willaime, J.-P. Crocombette, Irradiation-induced formation of nanocrystallites with C15 laves phase structure in bcc iron, Phys. Rev. Lett. 108, 025501 (2012). 


\title{
Microestructure Evolution in $\mathrm{Fe}$ and $\mathrm{FeCr}$ alloys with OKMC methods
}

\author{
M. J. Aliaga ${ }^{1}$, I. Martin-Bragado ${ }^{2}$, I. Dopico ${ }^{3}$, L. Malerba ${ }^{3}$, \\ M. Hernández-Mayoral ${ }^{4}$, M. J. Caturla ${ }^{1}$ \\ ${ }^{1}$ Dep. Física Aplicada, Universidad de Alicante, Spain \\ ${ }^{2}$ IMDEA Materials Institute, Getafe, Madrid, Spain \\ ${ }^{3}$ SCK-CEN, Belgium \\ ${ }^{4}$ CIEMAT, Madrid, Spain
}

MINOS, November 4-6, 2015 - Cadarache, France 


\section{Motivation:}

\section{validate models with ion implantation - extrapolate to neutron irradiation}

\section{Reproduce and explain ion and neutron implantation experiments in $\mathrm{Fe}$ and $\mathrm{FeCr}$}

Z. Yao, et al., Phil. Mag. 88, 2851 (2008)
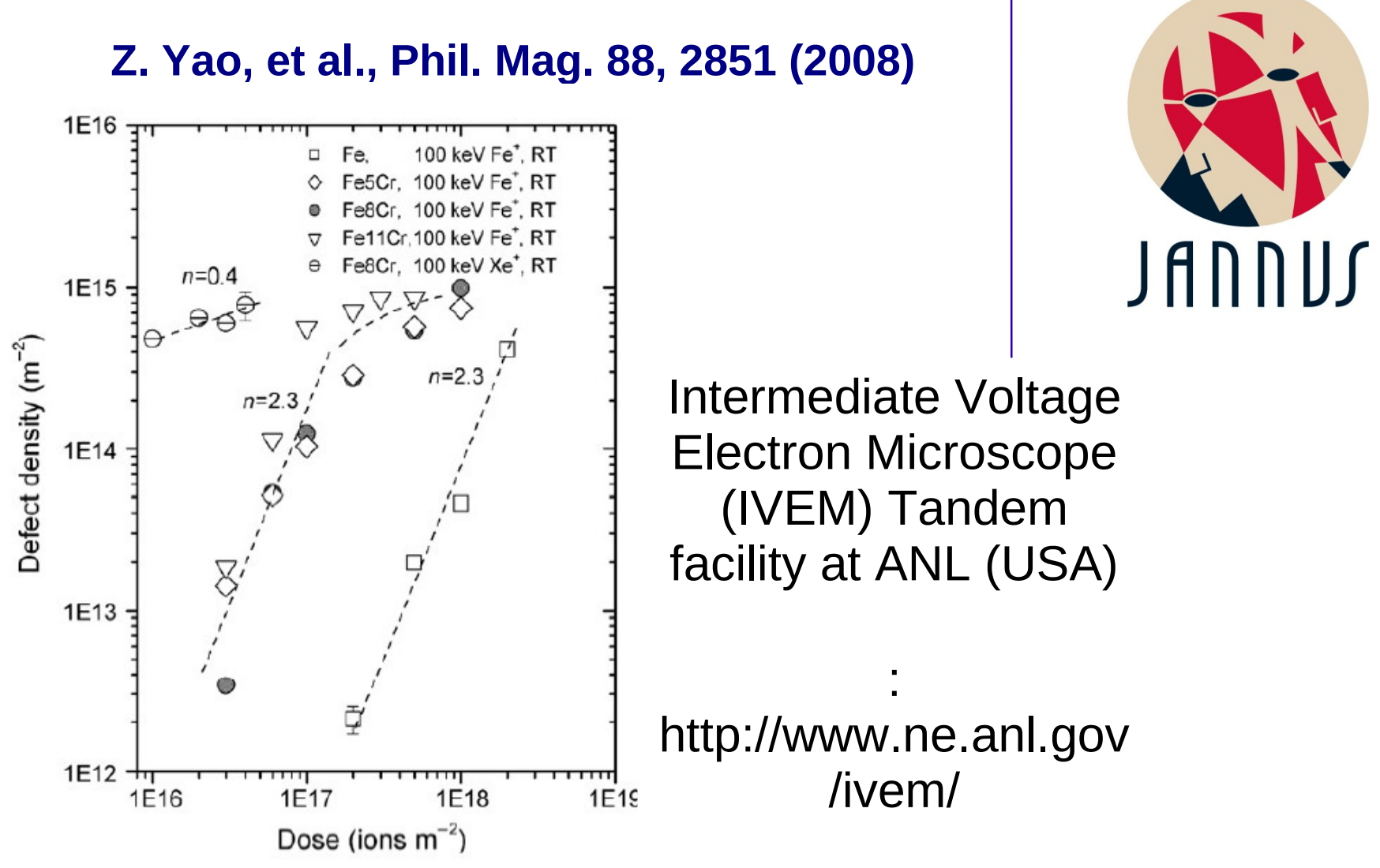

Intermediate Voltage Electron Microscope (IVEM) Tandem facility at ANL (USA)

http://www.ne.anl.gov http://jannus.in2p3.fr/

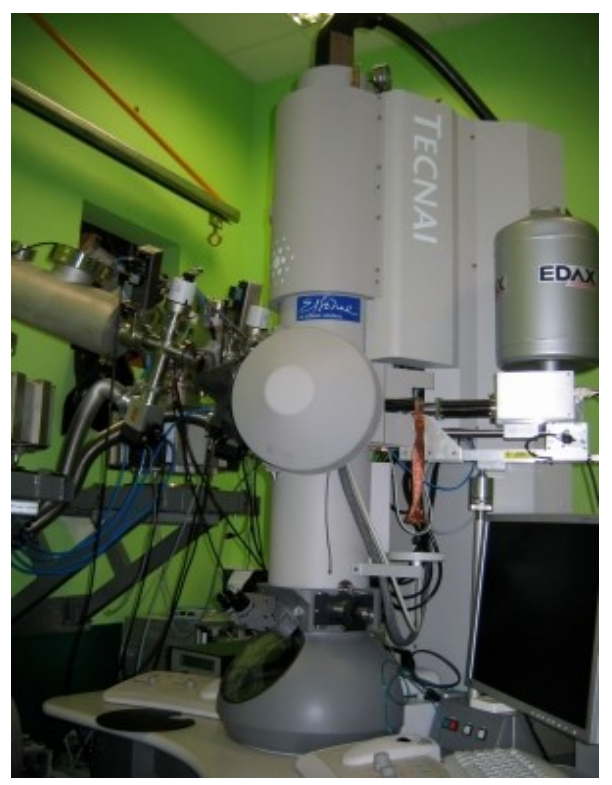

Universitat d'Alacant

A Universidad de Alicante 


\section{MD database + DFT data $\rightarrow$ OKMC $\rightarrow$ damage in bulk and thin films}

\section{MD \\ DFT}

100 keVe recoil in bulk

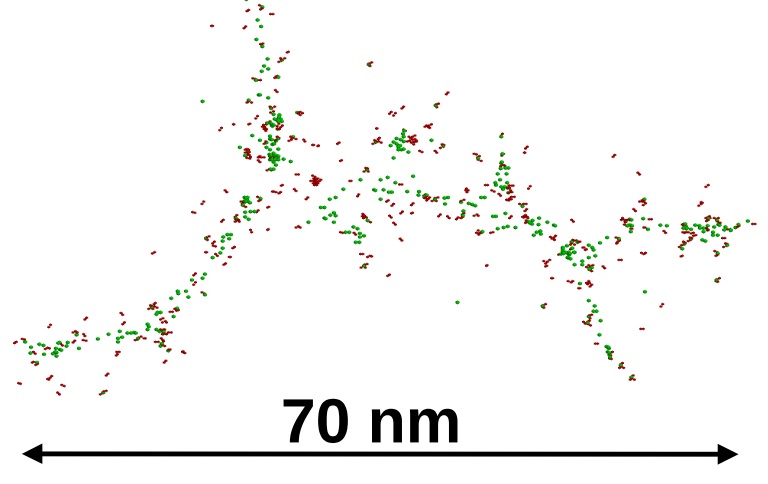

\section{$100 \mathrm{keV}$ Fe recoil in thin film}

- Interstitiáls

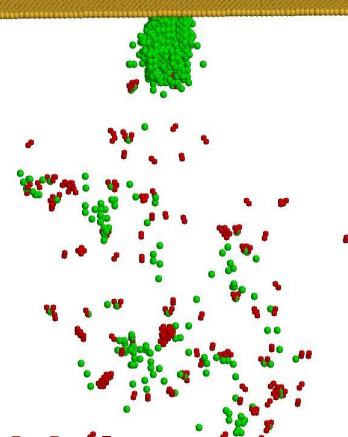

- Vacancies
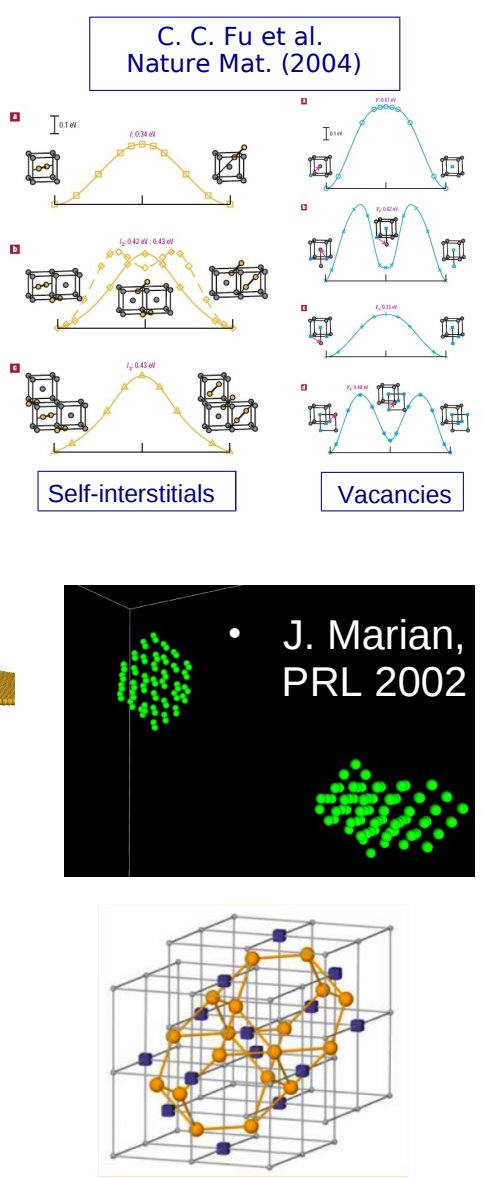

Marinica PRL (2012)

\section{OKMC}

\section{Exp}

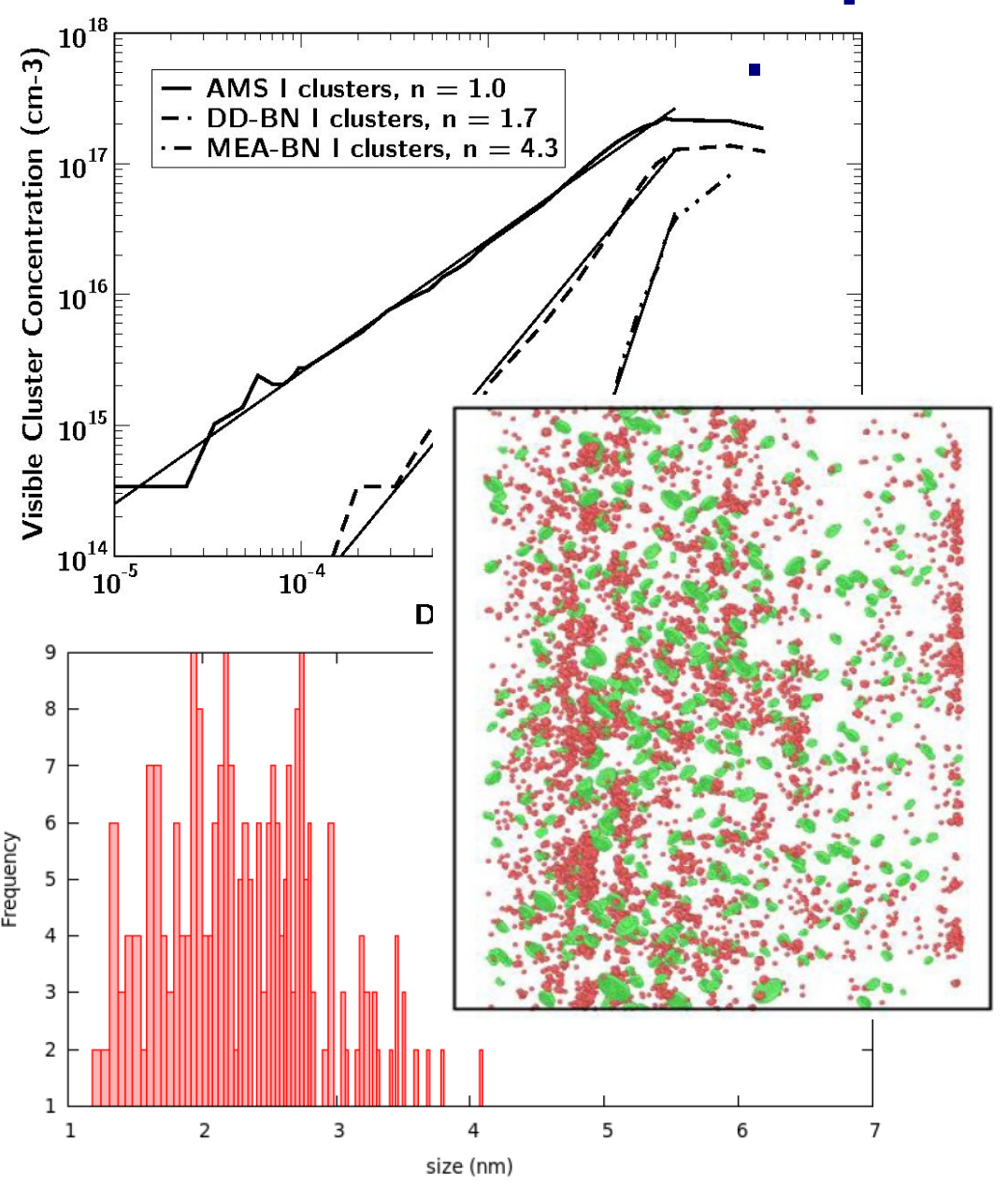

Universitat d'Alacant

$\triangleq$ Universidad de Alicante 


\section{New methods/models are emerging at all levels}

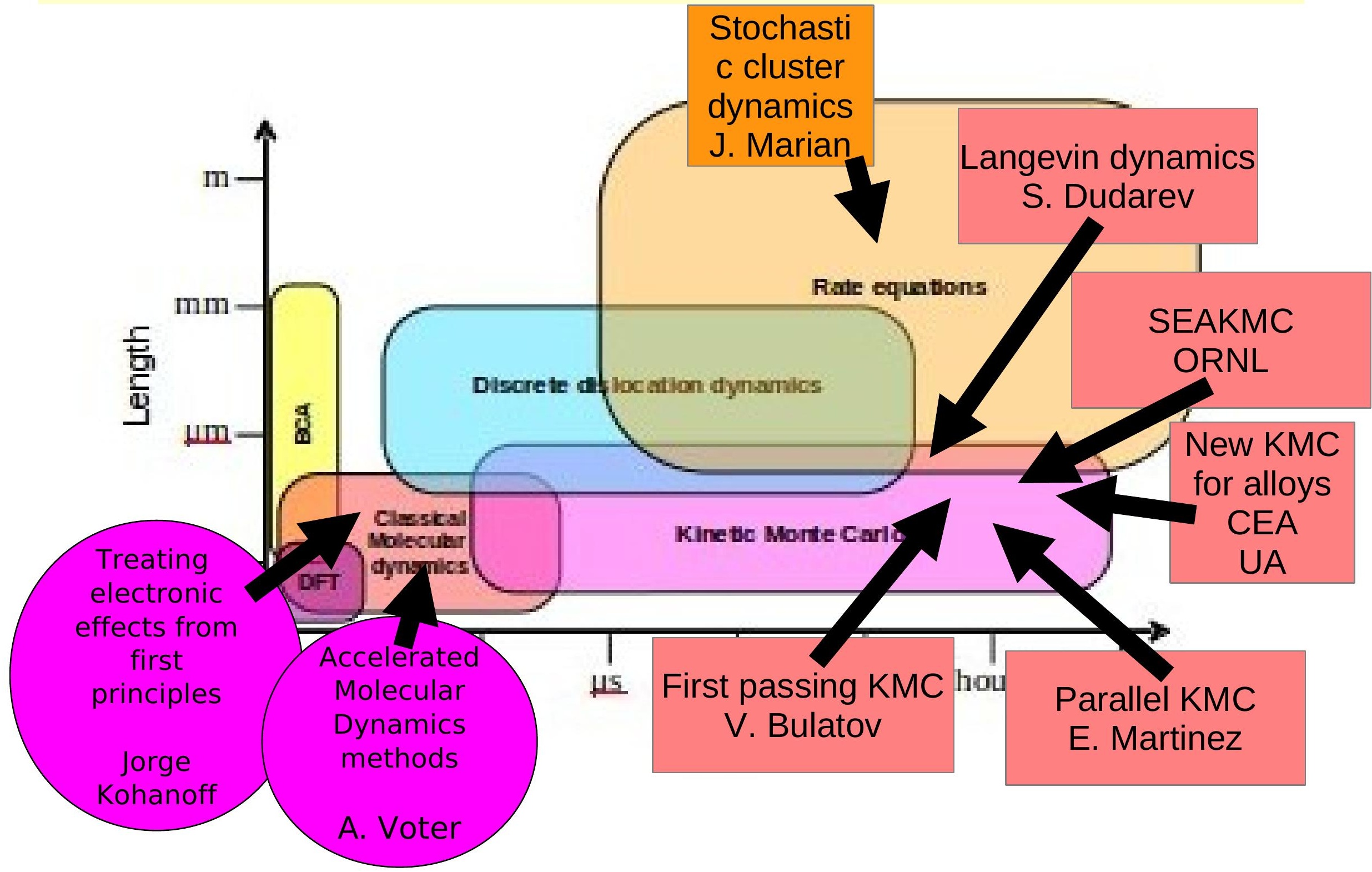




\section{Primary damage: influence on microstructure evolution}

bcc Fe

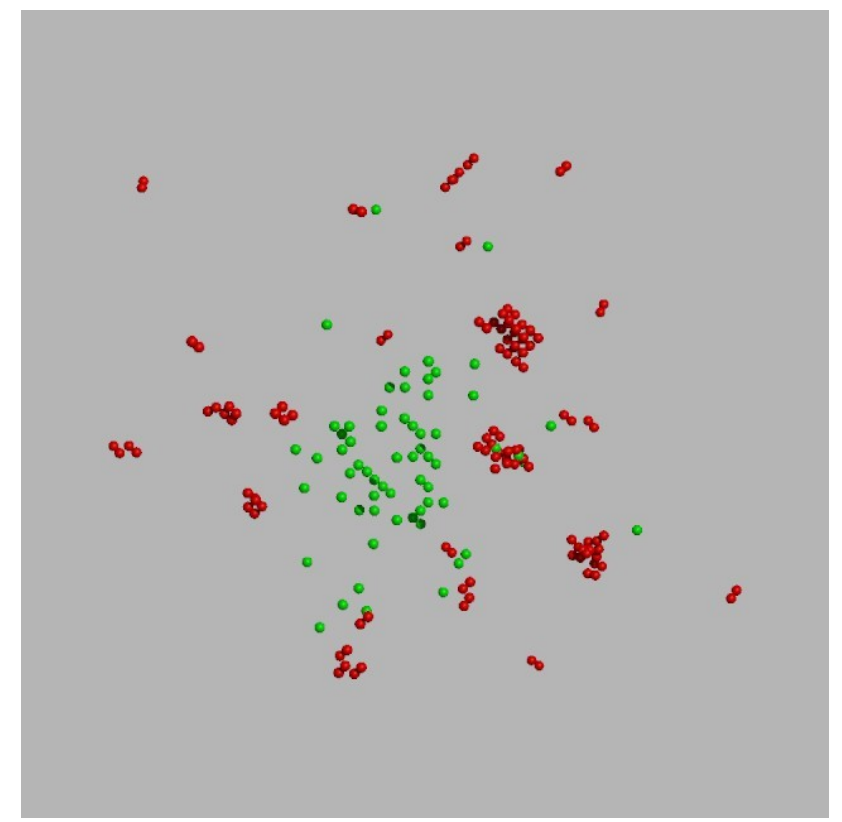

Fe 30keV, 66 defects fcc $\mathrm{Cu}$

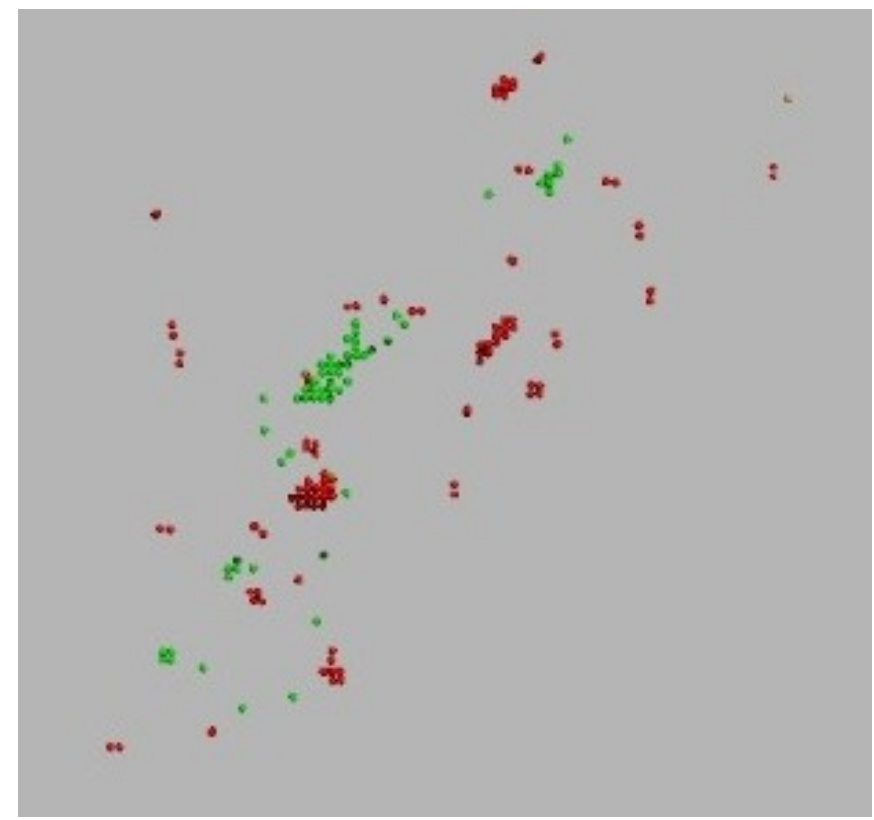

Cu 30keV, 69 defects

Similar number of defects but more vacancy clustering in $\mathrm{Cu}$ than in $\mathrm{Fe}$ This has important consequences in the subsequent damage evolution 


\section{Damage accumulation in $\mathrm{Cu}$ and $\mathrm{Fe}$}

Damage accumulation in $\mathrm{Cu}$ and Fe compared to experiments

Fe calculations $-\mathrm{N}$. Soneda

\section{Damage Accumulation in Copper}
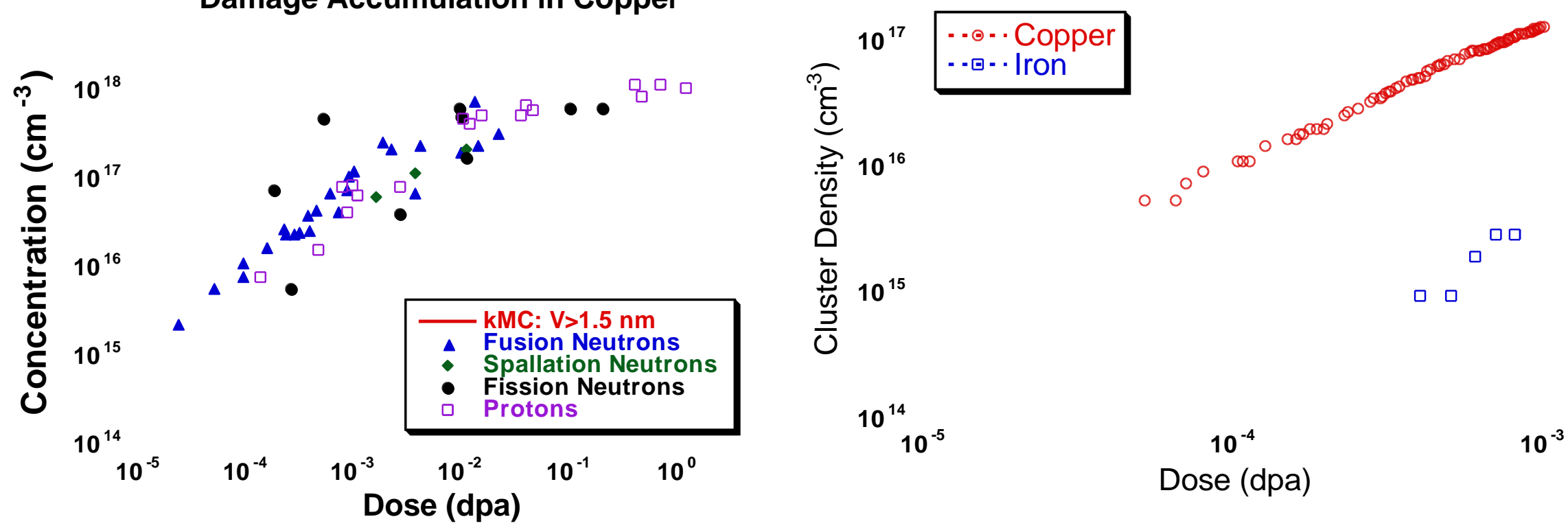

Simulations explain the basic differences observed experimentally in $\mathrm{Cu}$ and $\mathrm{Fe}$ :

nucleation of vacancy clusters in Cu together with fast migration of selfinterstitials, the presence of traps in Fe and the visibility under TEM

M. J. Caturla, N. Soneda, et. al, JNM 276, 12 (2000) 


\section{Influence of initial cascade damage distribution on damage accumulation (Carolina Björkas, Univ. Helsinki)}

Question addressed: Is the long term evolution of defects affected by the picosecond cascade damage distribution or does it only depend on migration and binding energies?

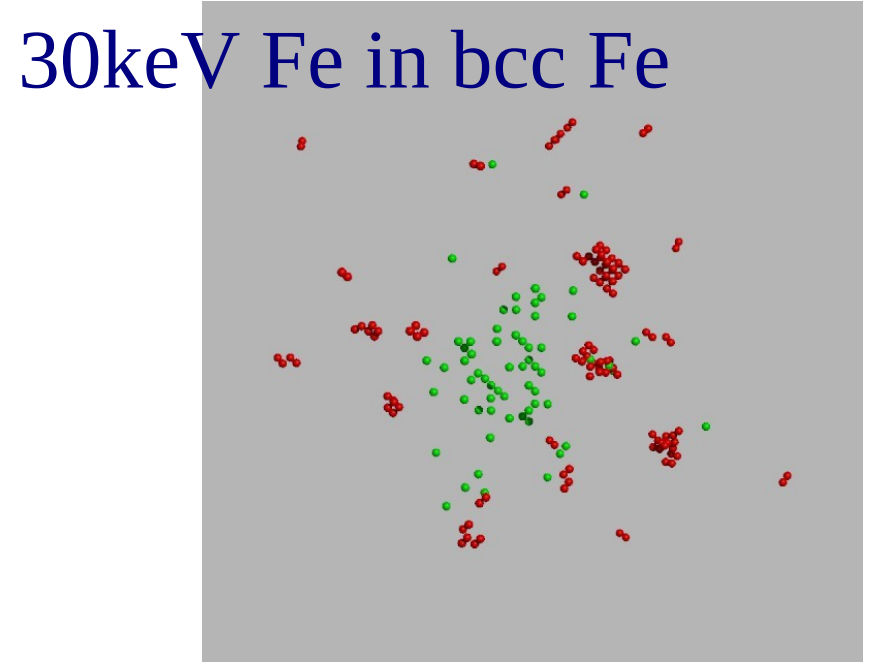

OKMC calculations using cascade damage distributions from 3 different interatomic potentials, AMS [1], DD-BN $[2,3]$ and MEA-BN $[3,4]$

[1] G. J. Ackland, M. I. Mendelev, et al. J. Physics: Condens. Matter, 16 (2004) [2] S. L. Dudarev and P. M. Derlet. J. Phys.: Condens. Matter, 17 (2005) [3] C. Bjorkas and K. Nordlund, Nucl. Instrum. \& Meth. B 259 (2007) [4] M. Muller, P. Erhart, and K. Albe, J. Phys.: Condens. Matter, 19 (2007)

NO EXPERIMENTAL VALIDATION OF MD RESULTS ON SINGLE CASCADE DAMAGE 


\title{
Influence of initial cascade damage distribution on damage accumulation (Carolina Björkas, Univ. Helsinki)
}

\author{
OKMC simulations
}

TOTAL DEFECT CONCENTRATION:

no significant difference between the three potentials

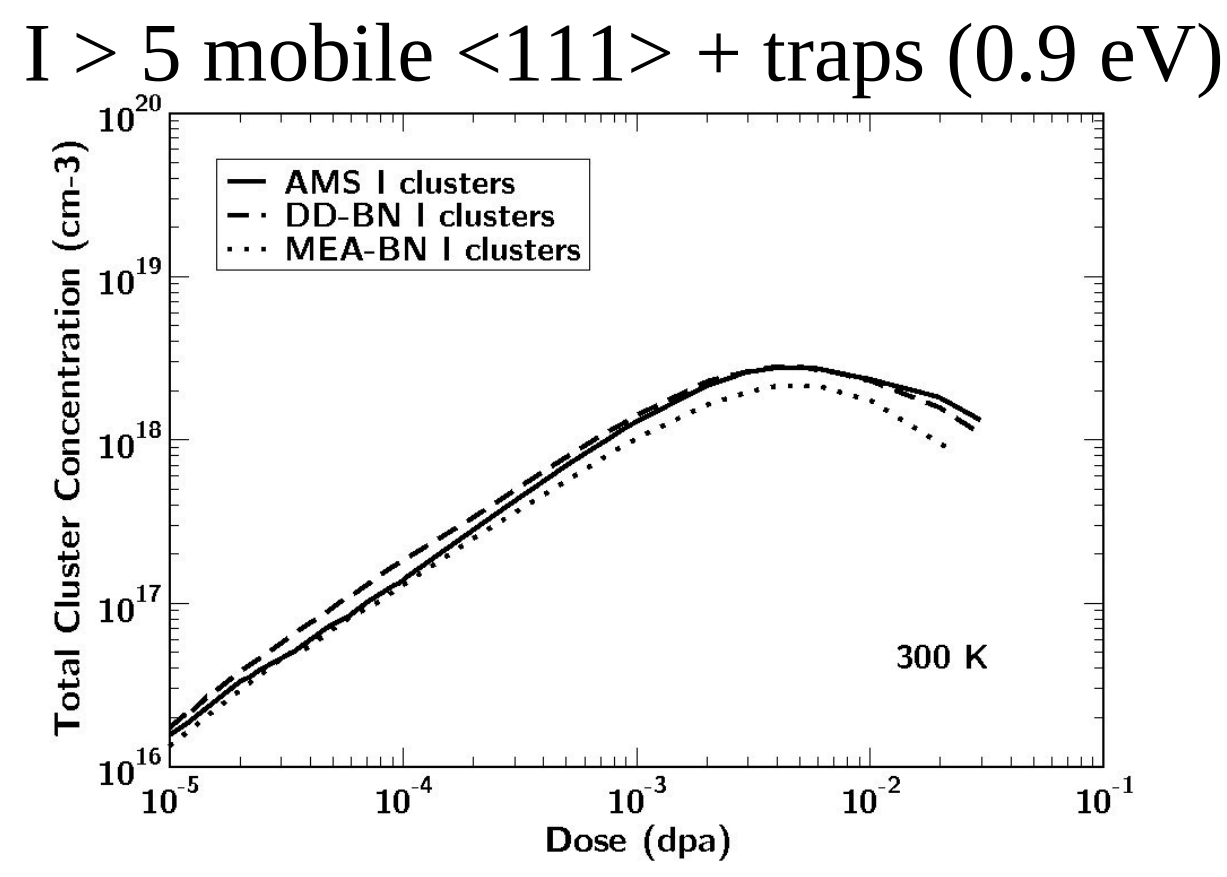




\section{Influence of initial cascade damage distribution on damage accumulation (Carolina Björkas, Univ. Helsinki)}

VISIBLE DEFECT CONCENTRATION:

only those clusters of interstitials $>55$ (loop of $1 \mathrm{~nm}$ radius)

only those clusters of vacancies $>350$ (void of $1 \mathrm{~nm}$ radius)

I $>5$ mobile $<111>$

+ traps $(0.9 \mathrm{eV})$

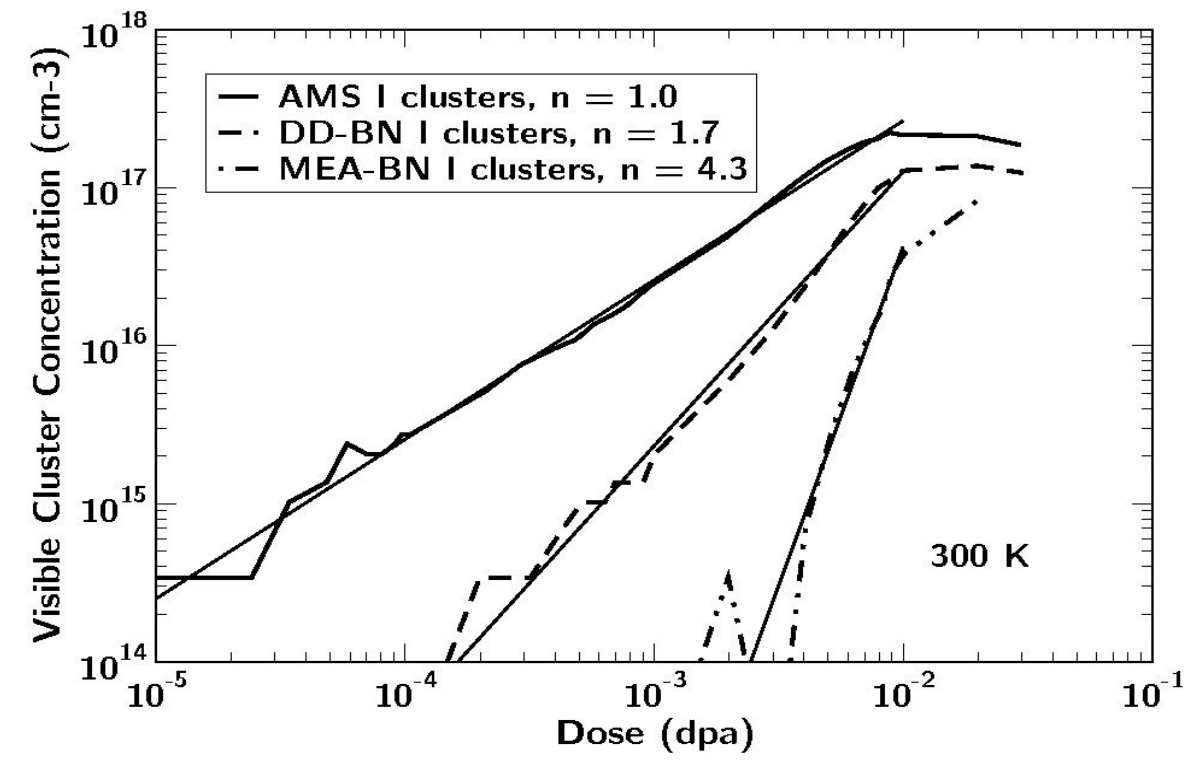

Large differences are now observed between the three potentials 


\section{Differences in cluster size distribution with int. potential (Carolina Björkas, Univ. Helsinki)}

SIA MEA Potential
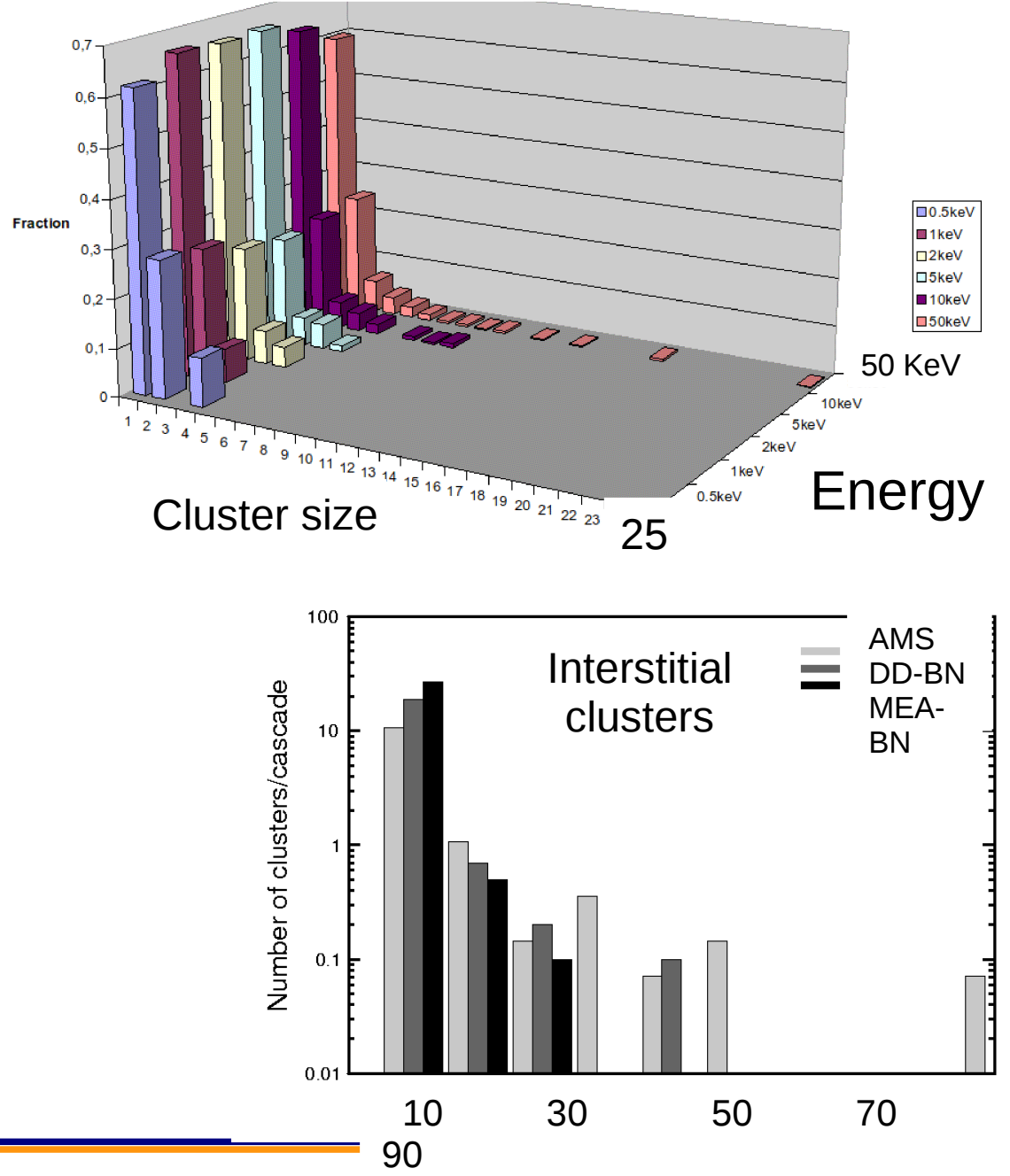

SIA AMS Potential

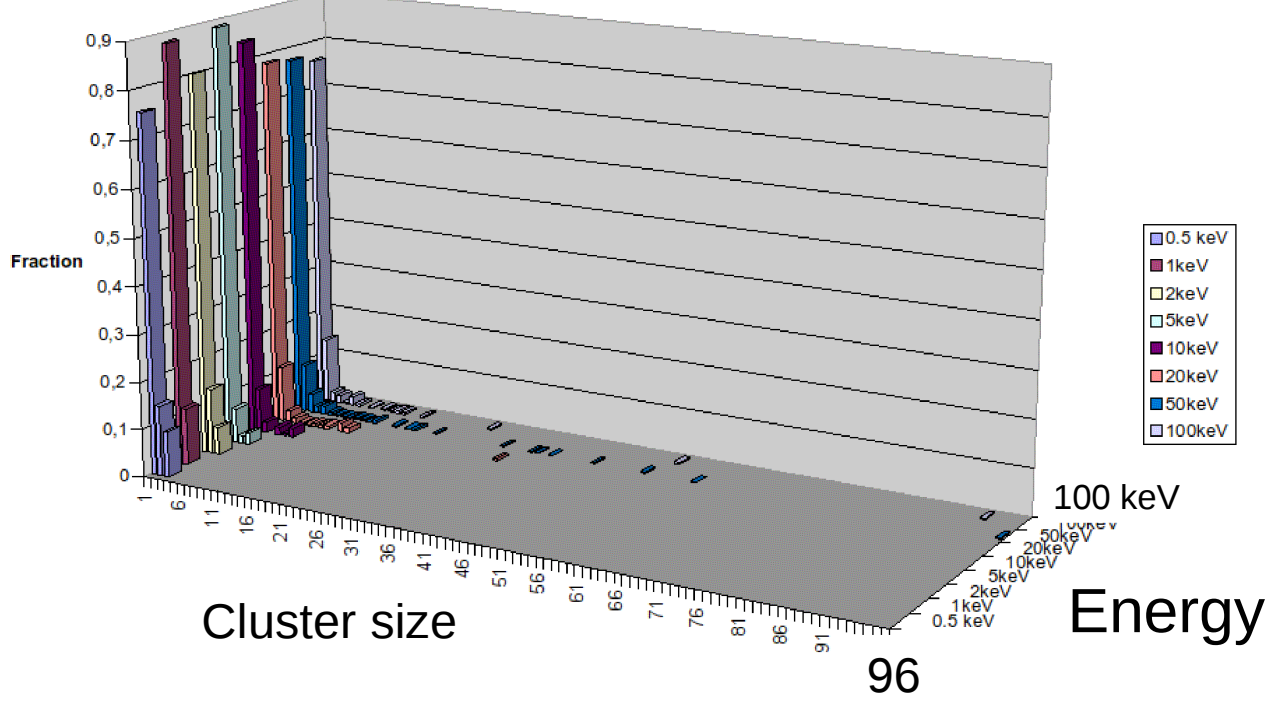

AMS potential predicts significantly larger selfinterstitial clusters at $50 \mathrm{keV}$ cascades

Cluster size

C. Björkas, et. al. Phys. Rev. B 85, 024105 (2012) 


\section{Experimental validation of models}

\section{Multiscale modeling_can only work with the proper experimental validation}

Z. Yao, et al., Phil. Mag. 88, 2851 (2008)

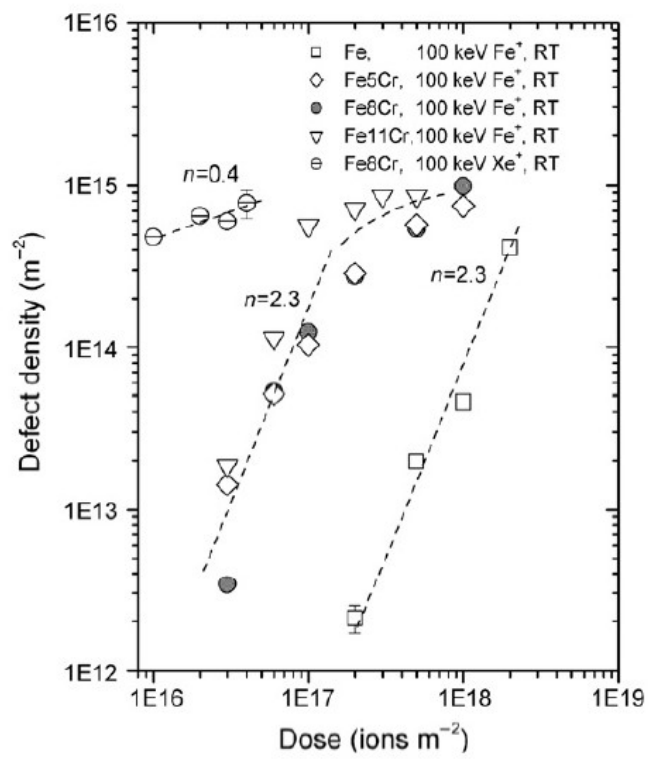

Intermediate Voltage Electron Microscope (IVEM) Tandem facility at ANL (USA)

http://www.ne.anl.go v/ivem/
In-situ TEM analysis of irradiation

What is the role of surfaces? 


\section{MD simulations of irradiation in Fe thin films Enhanced production of vacancy loops, mostly $<100>$}

Thin film irradiation with 100keV Fe ions

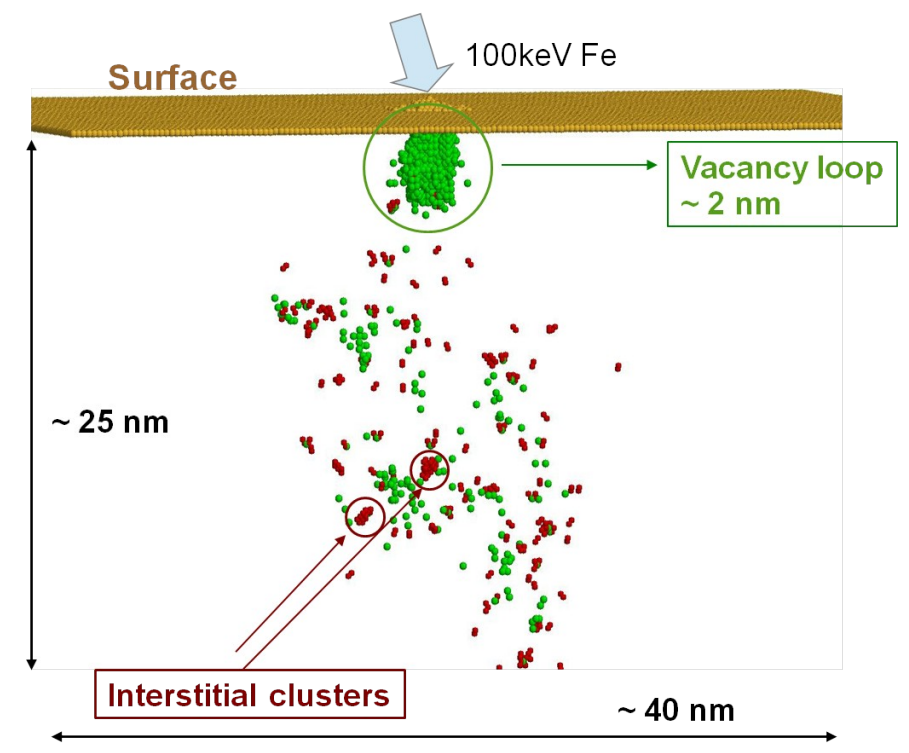

(a)

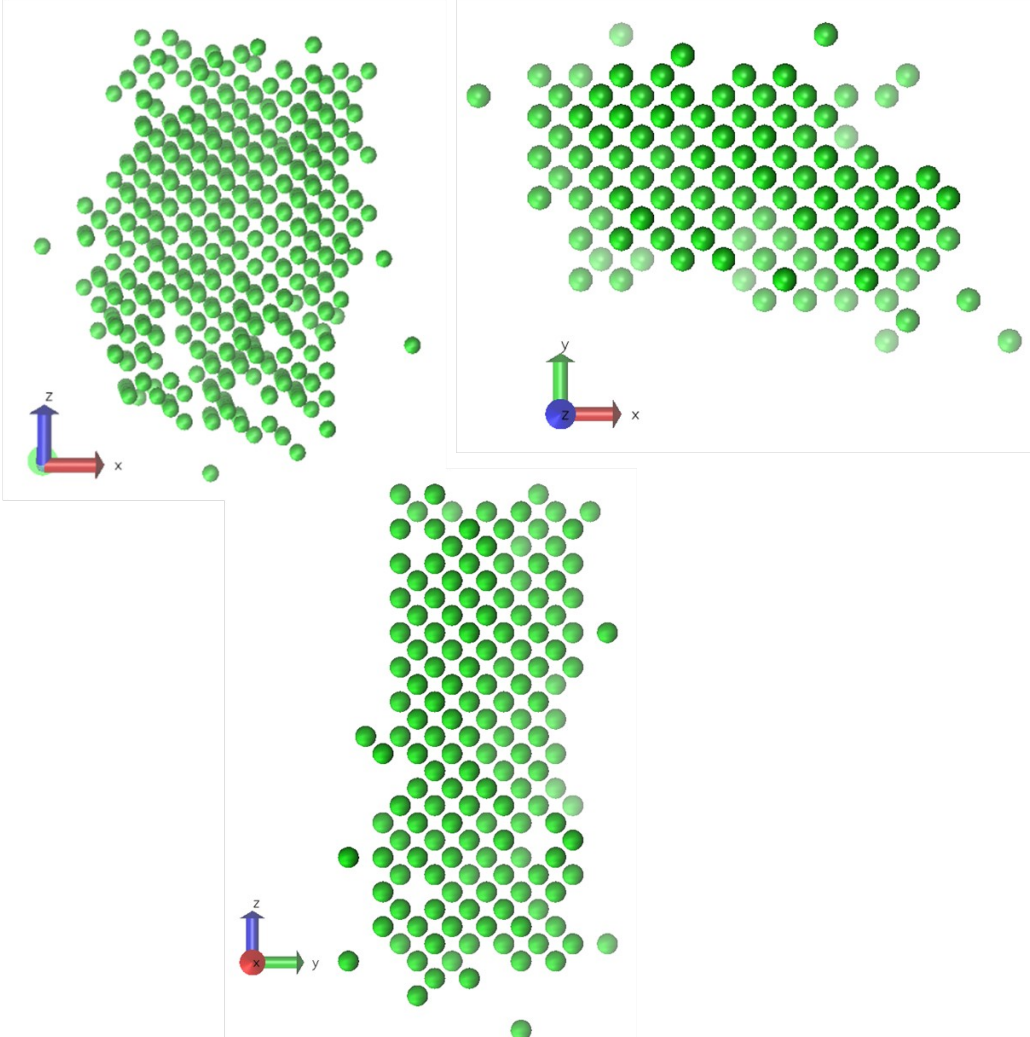

(b)

Irradiation of thin films at low energies $(50-150 \mathrm{keV})$ show the formation of large $(\sim 1 \mathrm{~nm}$ radius $)<100>$ vacancy loops. Mostly square loops as expected from energy considerations (Gilbert et al J.Phys:Cond.Mat. 2008) 


\section{Simulating damage in metals: surface vs. bulk irradiation}
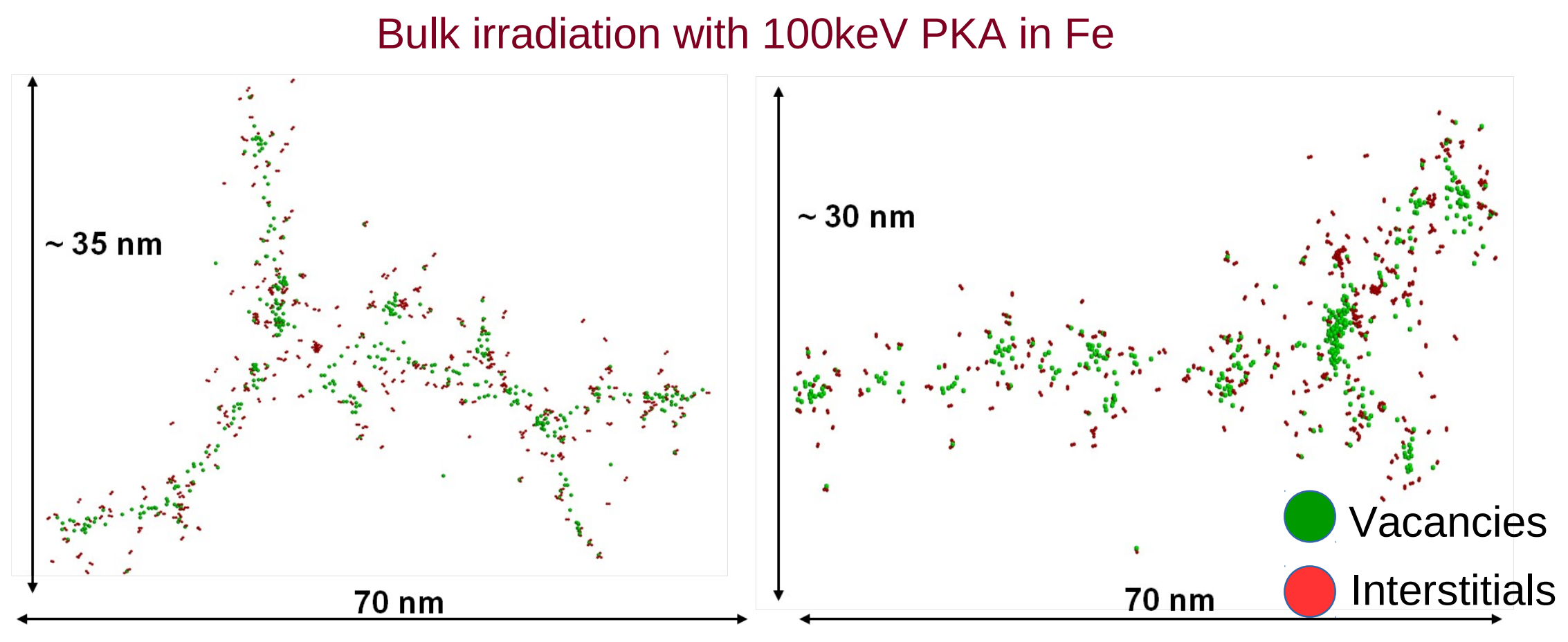

(a)

(b)

- Bulk irradiation shows the formation of self-interstitial loops

- Some large vacancy loops are also observed.

- Note the sub-cascade formation 


\section{Statistical analysis of MD cascades}

Cluster size differences between bulk and thin films

$50 \mathrm{keV}$, vacancies

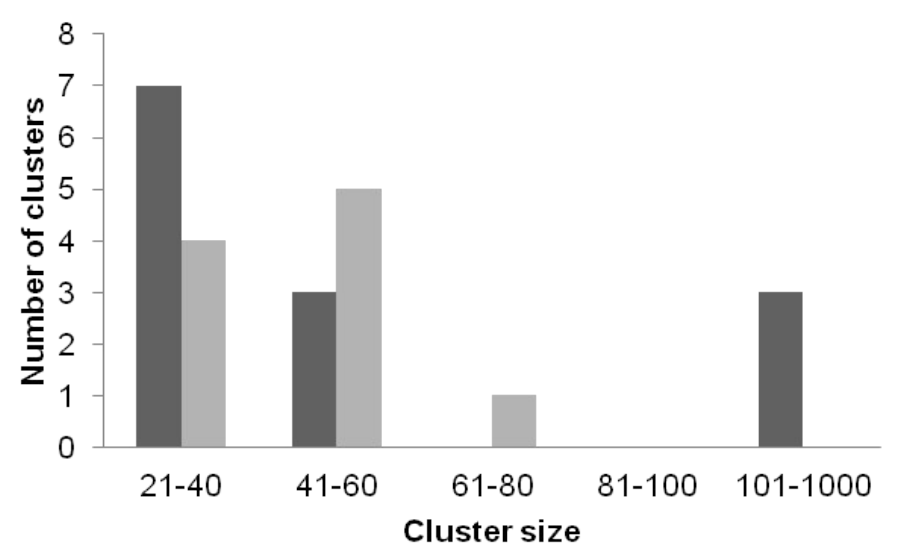

(a)
$50 \mathrm{keV}$, interstitials

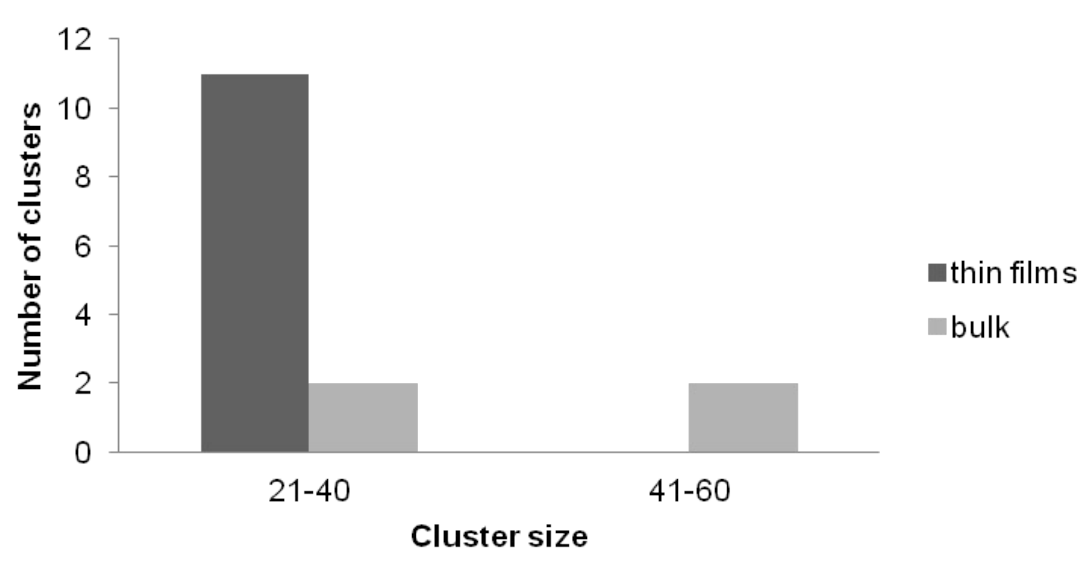

(b)

- Significant difference between the size of the clusters in bulk and thin films for the same energy

- Vacancy clusters much larger in thin films (> 100 defects)

- Self-interstitial clusters significantly larger in bulk irradiation 


\section{Damage produced by $\mathrm{Ga}$ ions in Fe at low energies (30keV)}

Thin film irradiation with 30keV Ga ions

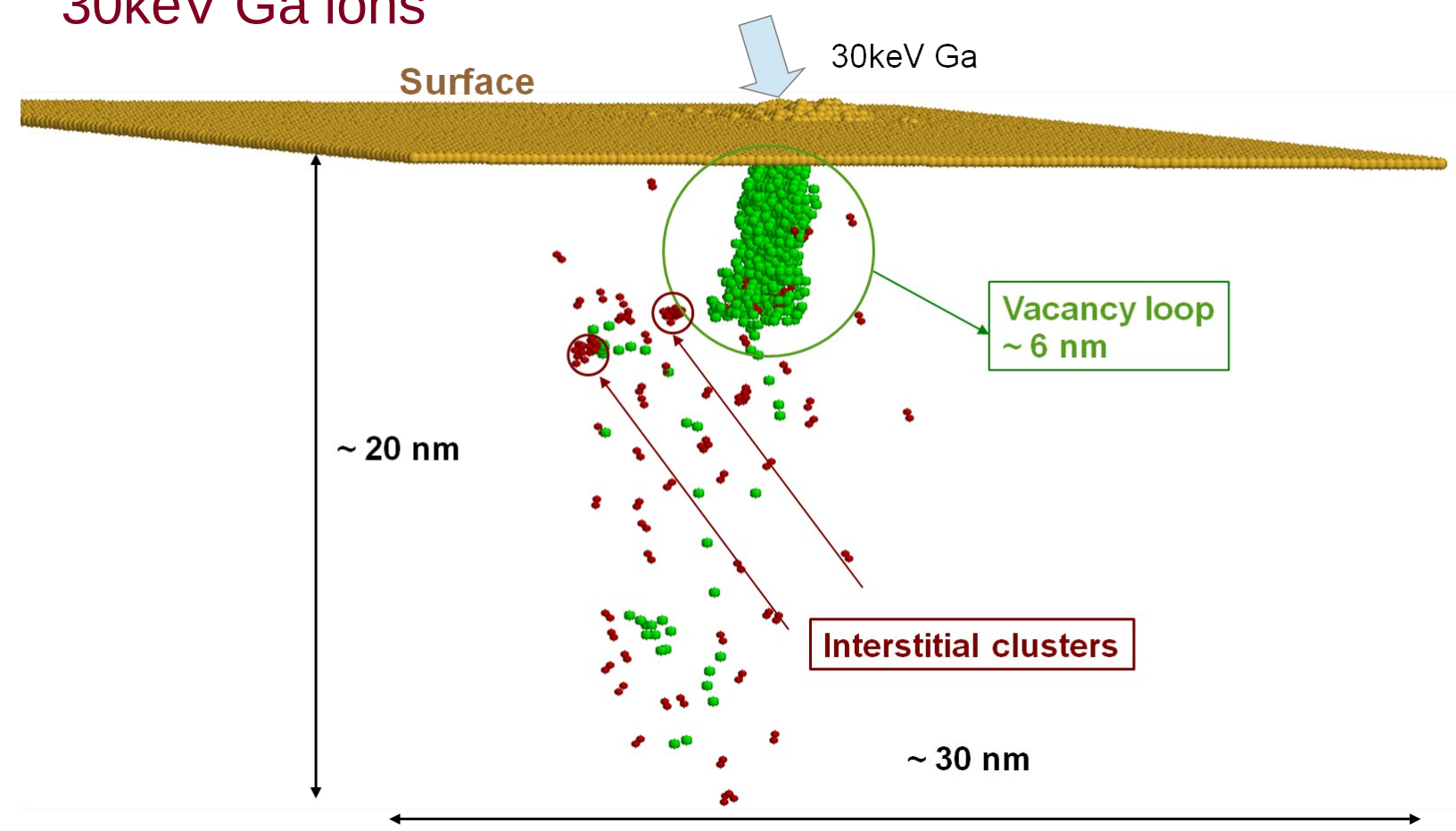

Heavier ion $(\mathrm{Ga})$ produces much larger vacancy clusters also of $<100>$ type even at lower energies (30 keV), in agreement with experiments, $M$. L. Jenkins Nature (1976) \& Z. Yao Phil. Mag. 2008 


\section{Modeling damage accumulation in Fe: OKMC}

\section{M onca}

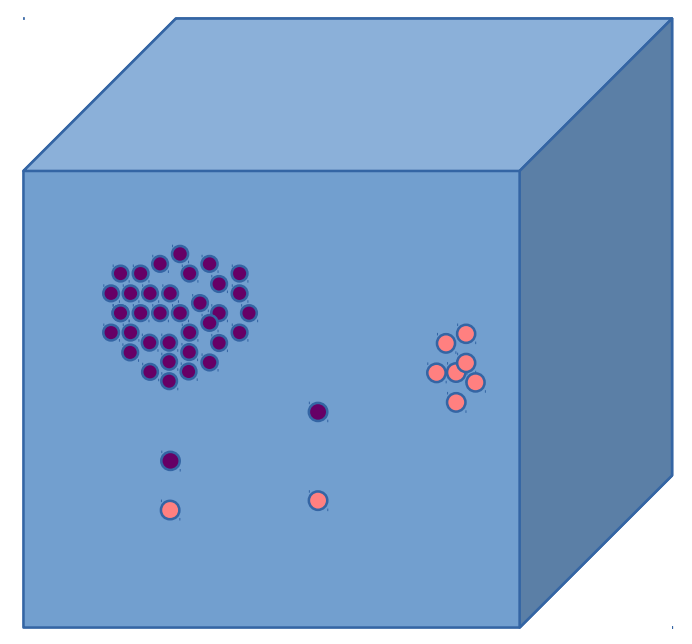

MMonCa - OKMC code

All individual defects can be resolved
OKMC code - MMonCa from IMDEA-Materials

I. Martin-Bragado, et. al. Computer Physics Comunications (2013). I www.materials.imdea.org/MMonCa

\section{Small defects}

Vacancies and Self-interstitials up to 4 Energetics from C. C. Fu, Nat. Mat. 4 (2005) 68

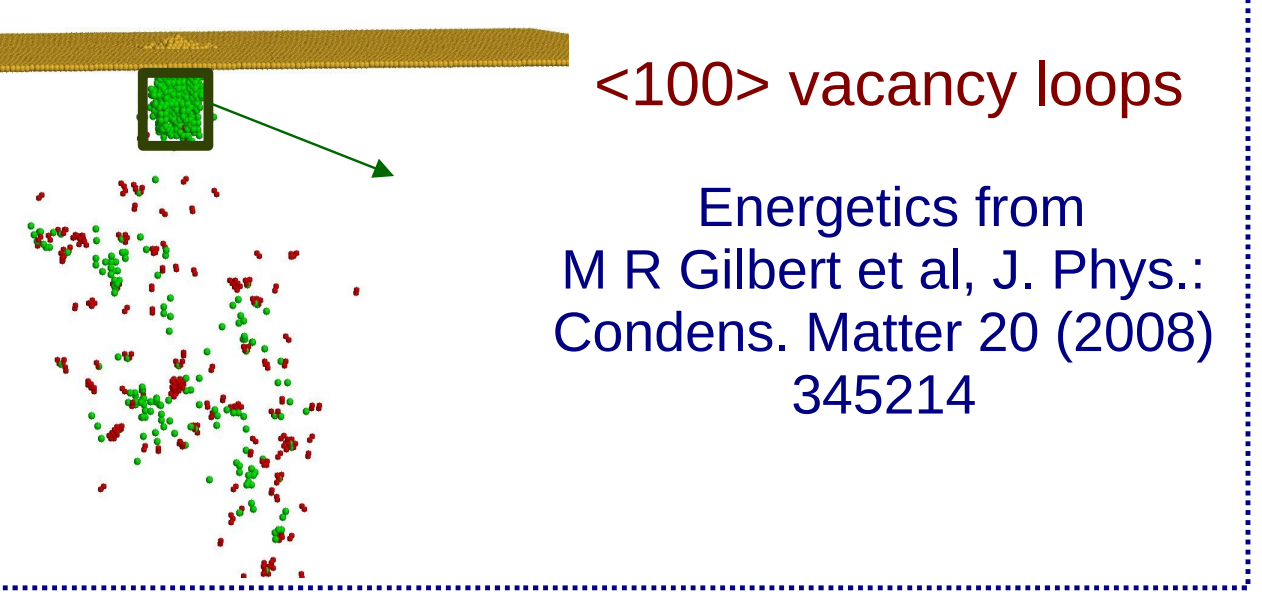




\section{Defect-defect interaction in OKMC $<100>$ vs. $<111>$ self-interstitial loops}

$100 \mathrm{keV} F e$ implantation in thin film

Model A

J. Marian [1]

D. Terentyev [2]

Formation of $<100>$ by interaction between $<111>$ loops

of the same size

\section{Model B}

Marinica [3]

Growth of two independent loop

populations

$5 \%<100>-95 \%<111>$

[1] J. Marian et al. PRL 88, 25 (2002).

[2] H. Xu, R. Stoller, Y. Osetsky, D. Terentyev, PRL 110, 265503 (2013).

[3] M.-C. Marinica, F. Williaime, J.-P. Crocombette, PRL 108, 025501 (2012).

[4] N. Soneda, T. Diaz de la Rubia, Phil. Mag. A 81 (2001) 331

$<111>$ loop mobility from
Soneda [4]
$<100>$ loops immobile




\section{OKMC of $100 \mathrm{keV} \mathrm{Fe}$ implantation in $\mathrm{Fe}$ and $\mathrm{FeCr}$ Reference experiments}

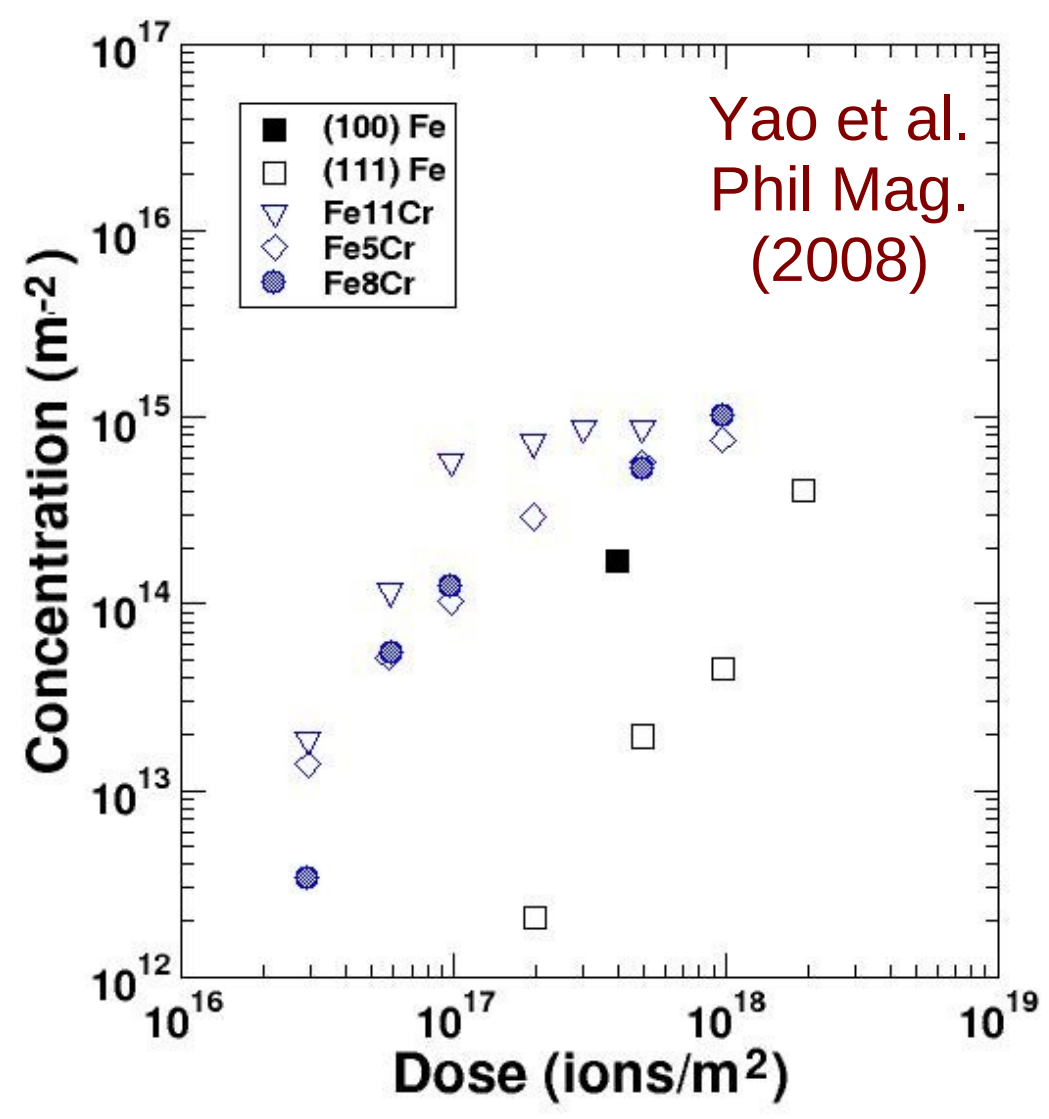

- Thickness 50nm

- Pure Fe: mostly <100> loops at low dose

- FeCr: mostly <111> loops

Evaluate the defects obtained from the two models

Effect of different parameters:

Mobility of $<100>$ loops

-Model A: minimum <111> loops to <100>

Model B: ratio of $<100>$ vs. $<111>$ loops

-Presence of traps (binding of $0.8 \mathrm{eV}$ )

Mobility of $<111>$ loops 


\section{OKMC of $100 \mathrm{keV} \mathrm{Fe}$ implantation in $\mathrm{Fe}$ and $\mathrm{FeCr}$ $<100>$ Vacancy loops}

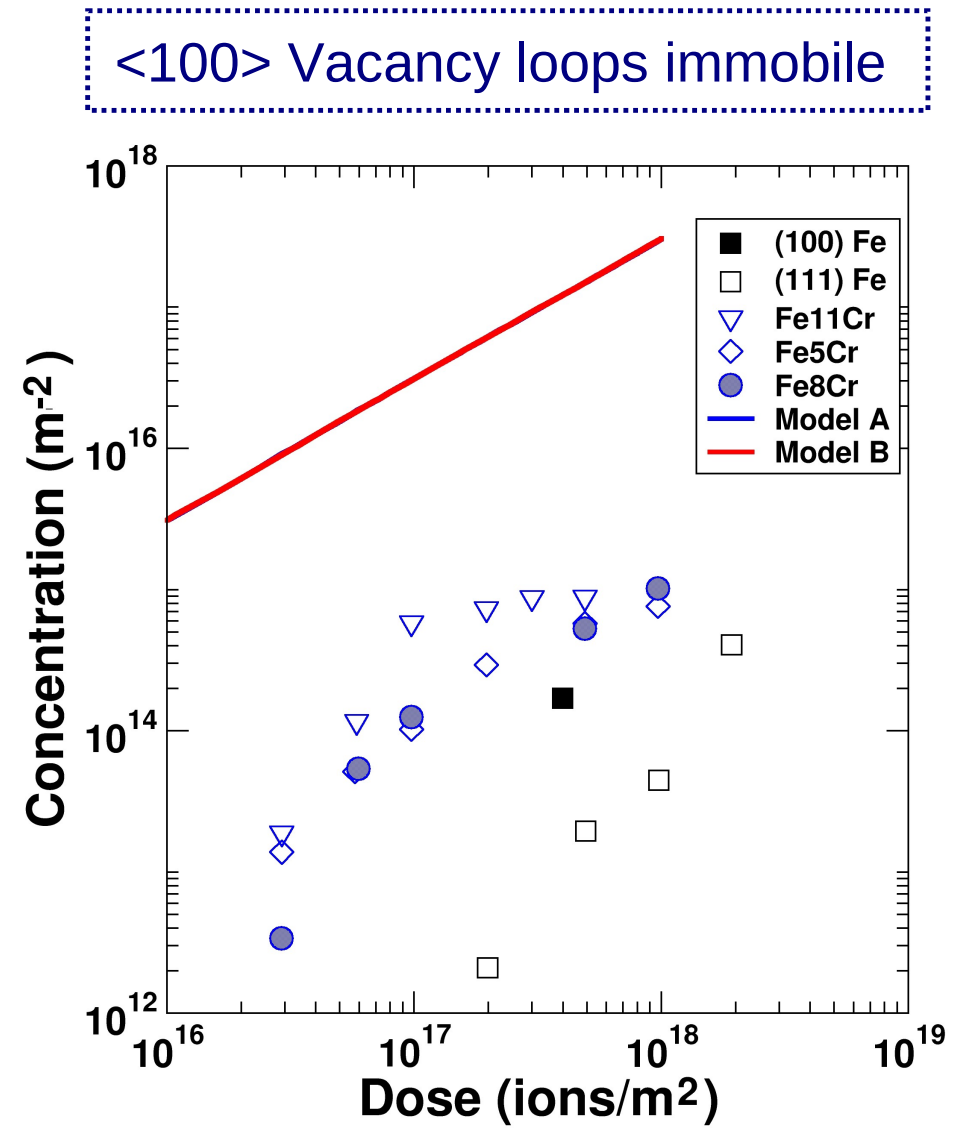

Concentrations too high compared to experimental measurements

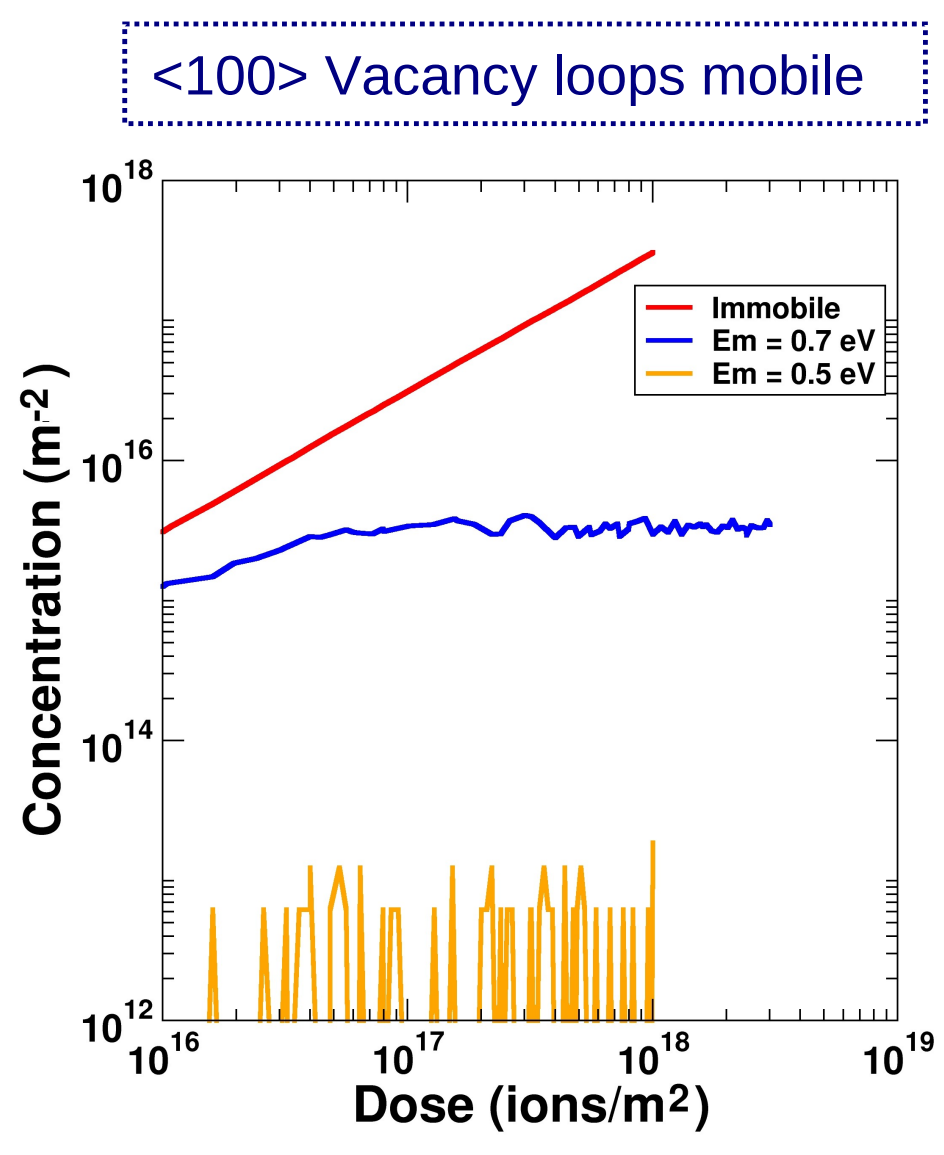

Considering a mobility of $0.5 \mathrm{eV}$ low concentration of $<100>\mathrm{V}$ loops 


\section{OKMC of $100 \mathrm{keV} \mathrm{Fe}$ implantation in $\mathrm{Fe}$ and $\mathrm{FeCr}$ Model A vs. Model B - no Carbon}

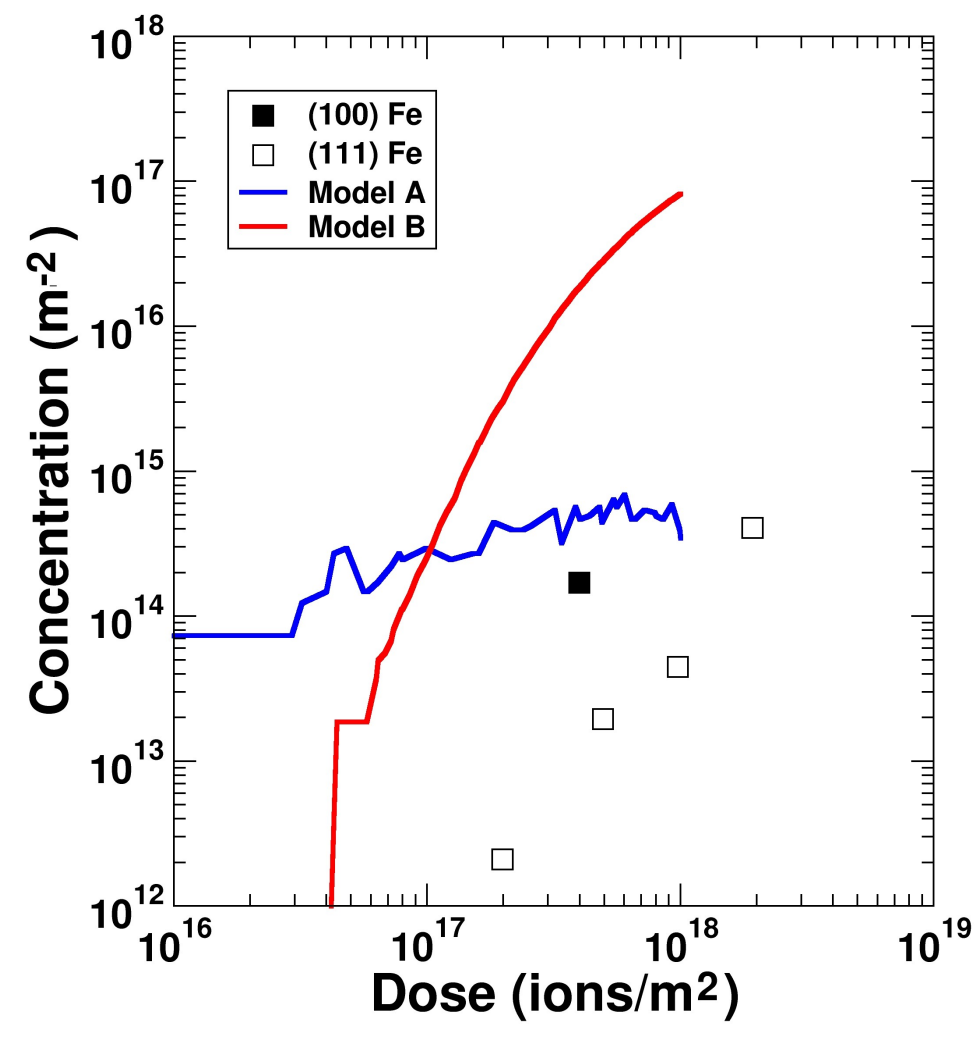

$$
\begin{aligned}
& \text { Model A: }<111>+<111>-><100> \\
& \text { Model B: } 5 \%<100>, 95 \%<111>
\end{aligned}
$$

Without Carbon all loops are of $<100>$ type with both models

Concentrations are too high compared to experimental measurements

Dose dependence closer to experiments in the case of Model B 


\section{OKMC of $100 \mathrm{keV} \mathrm{Fe} \mathrm{implantation} \mathrm{in} \mathrm{Fe}$ and $\mathrm{FeCr}$ Model B - effect of initial distribution of loops}

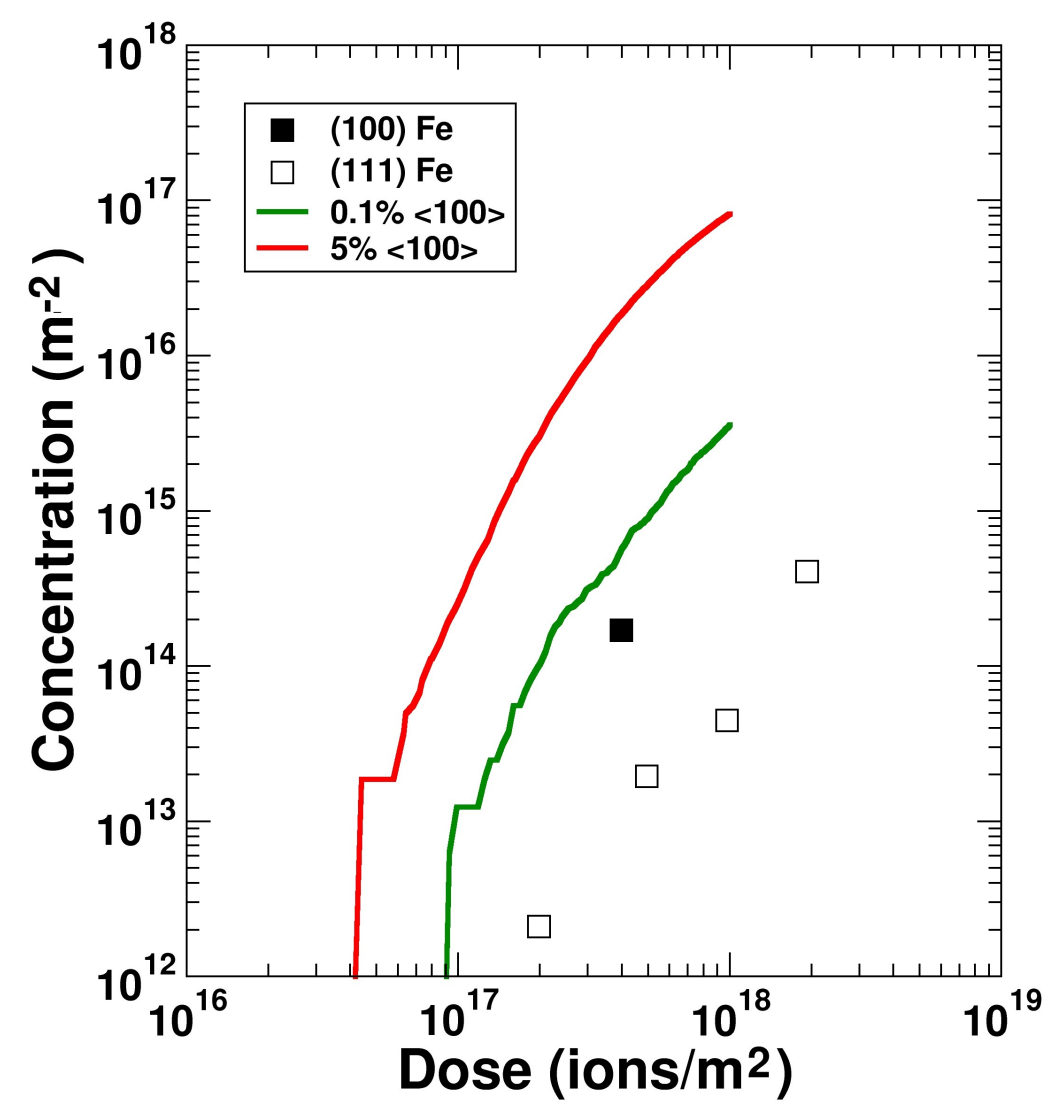

Model B:

- $5.0 \%<100>, 95.0 \%<111>$

- $0.1 \%<100>, 99.9 \%<111>$

Distribution of only $0.1 \%$ of the small Interstitial clusters $(<4)$ as seeds for $<100>$ loops gives loops concentrations in closer agreement

to experimental values for (100) orientation

Rate of growth of loops with dose in agreement with experimental measurements 


\section{OKMC of $100 \mathrm{keV} \mathrm{Fe}$ implantation in $\mathrm{Fe}$ and $\mathrm{FeCr}$ Model B - effect of <111> mobility}

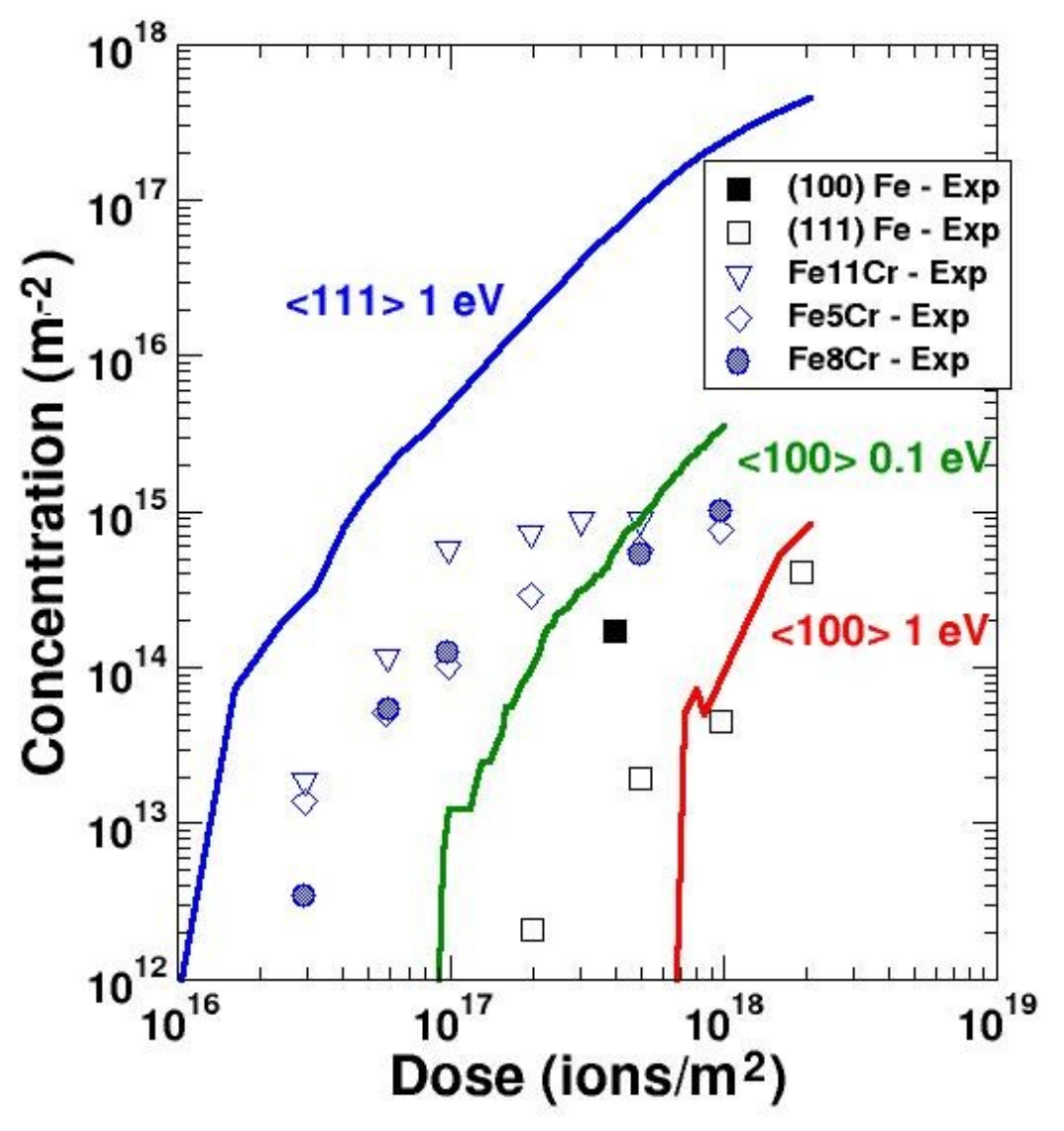

Model B:

- <111> $\mathrm{E}_{\mathrm{m}} \sim 0.1 \mathrm{eV}$

- $<111>E_{m}=1 \mathrm{eV}$

Two population of loops:

$$
<111>\text { and }<100>
$$

Densities close to values for $\mathrm{FeCr}$

$$
\text { More }<111>\text { than }<100>\text { loops }
$$

Problems with the saturation of loops at high doses:

loop-loop interaction capture radius or long range interactions must be reviewed 


\section{OKMC model for concentrated alloys}

1. The alloying element is not treated discretely but in terms of concentration

2. Jump rates of particles are not fixed: will depend on the location of the particle and the enviroment.

\begin{tabular}{|l|l|l|}
\hline $\mathbf{1}$ & $\mathbf{2}$ & $\cdots$ \\
$\mathbf{C}_{1}$ & $\mathbf{C}_{2}$ & \\
\hline$\cdots$ & $\mathrm{i} \mathrm{C}_{\mathrm{i}}$ & $\begin{array}{l}\mathrm{i}+1 \\
\mathrm{C}_{\mathrm{i}+1}\end{array}$ \\
\hline & $\cdots$ & $\begin{array}{l}\mathrm{N} \\
\mathrm{C}_{\mathrm{N}}\end{array}$ \\
\hline
\end{tabular}
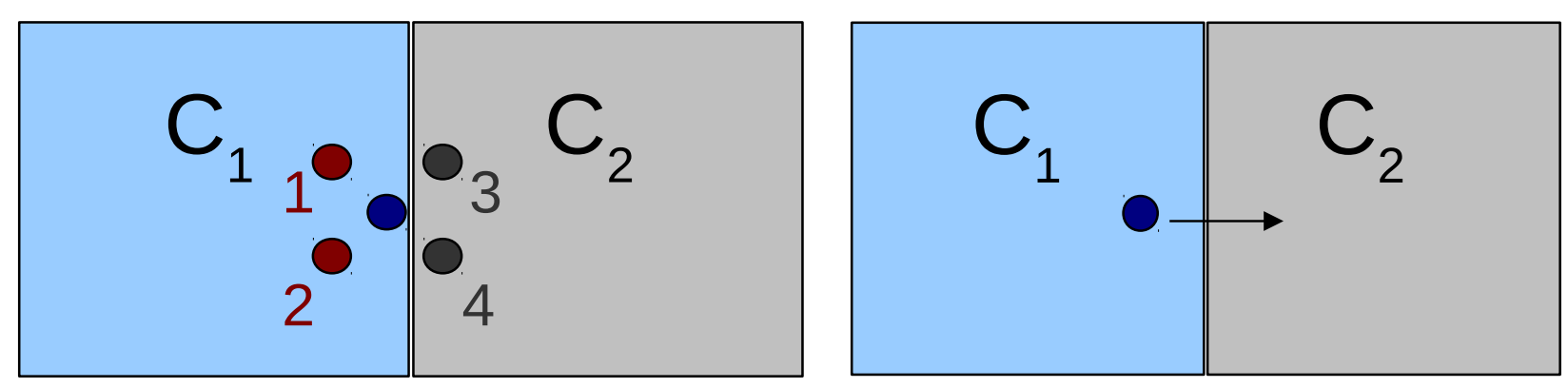

\section{MALERBA \& M. J. CATURLA}




\section{Do all these mechanisms just add up? $1+1=2$ ?}
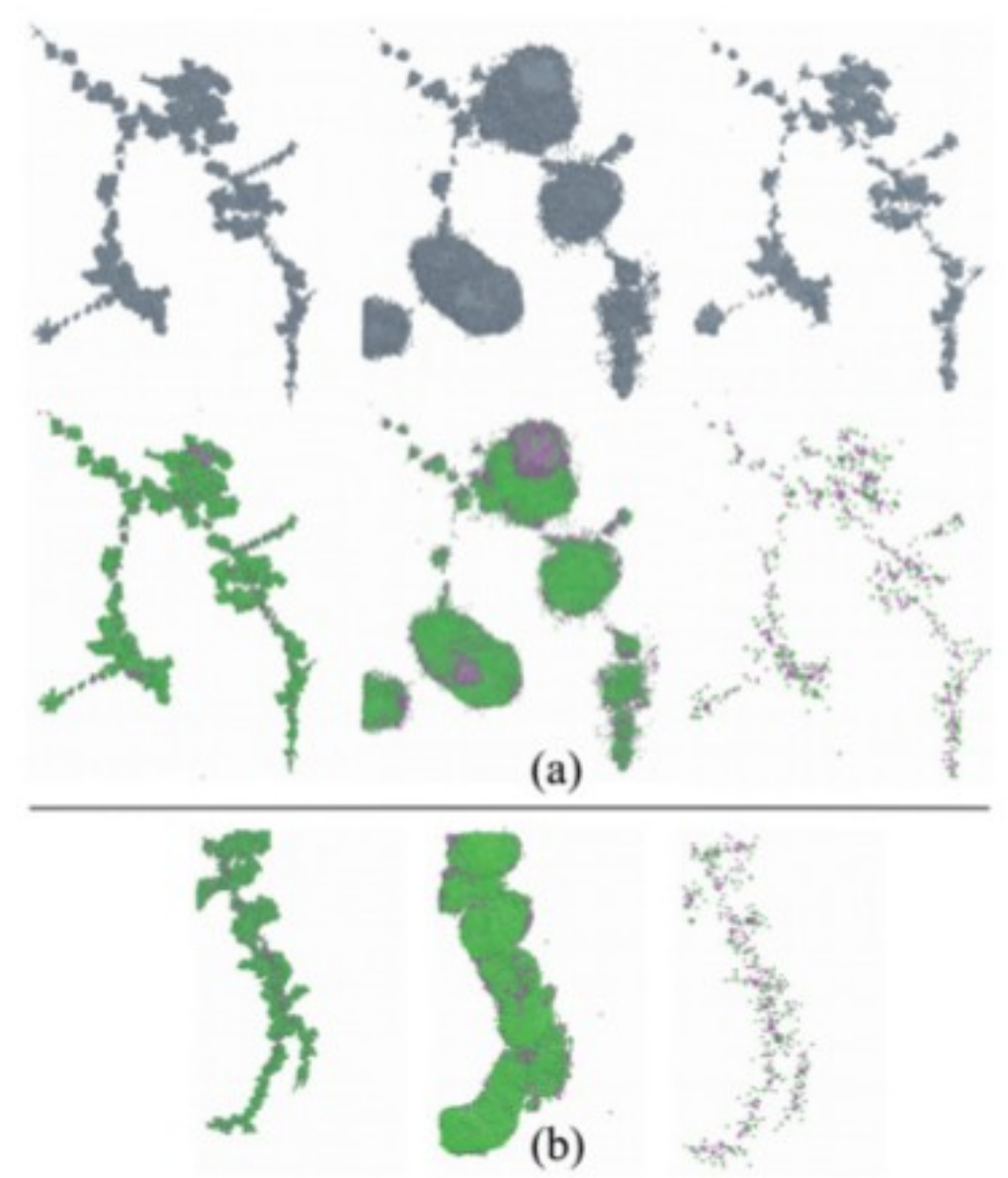

500 kev cascade in Fe

E. Zarkadoula et al, J. Phys. Condense. Matter 25 (2013) 125402 


\title{
Simulating interfaces and complex systems
}

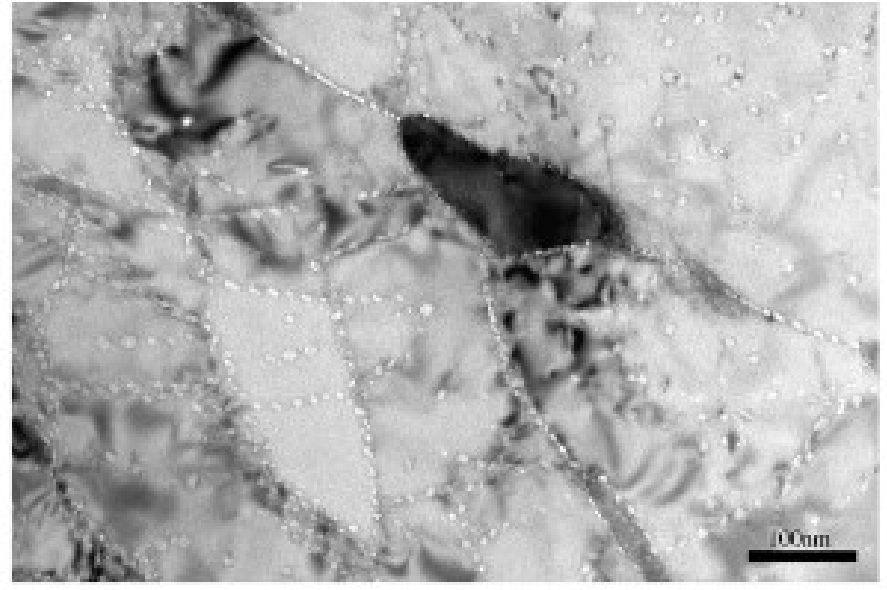

What we want to achieve:

\author{
Modeling concentrated \\ alloys, interfaces (grain \\ boundaries) and \\ precipitates (ODS)
}

Fréchard et. al. JNM (2009) TEM image of a martensitic steel after He implantation 


\section{Conclusions}

- Primary damage plays a major role in the subsequent microstructure evolution

- Surface effects must be taken into account when comparing to in-situ TEM ion implantation:

- Damage production could be affected by the presence of surfaces (low energy irradiation)

- Damage evolution will be affected due to preferential trapping by surfaces or image forces.

- More complex and detail simulations: loop size and type.

- New methods emerging at all levels to study complex systems: alloys, electronic effects... 


\section{Acknowledgements}

The research leading to these results is partly funded by the European Atomic Energy Community's (Euratom) Seventh Framework Programme FP7/2007-2013 under grant agreement No. 604862 (MatISSE project) and in the framework of the EERA (European Energy Research Alliance) Joint Programme on Nuclear Materials

\section{OMATISSE}

This work has been carried out within the framework of the EUROfusion Consortium and has received funding from the Euratom research and training programme 2014-2018 under grant agreement No 633053. The views and opinions expressed herein do not necessarily reflect those of the European Commission. 